\title{
The costs of traumatic head injury and associated factors at University of Gondar Specialized Referral Hospital, Northwest Ethiopia
}

Yilak Asmamaw ${ }^{1}$, Mezgebu Yitayal ${ }^{2}$, Ayal Debie $^{2}$ and Simegnew Handebo ${ }^{3 *}$

\begin{abstract}
Background: Head injuries account for 650,000 annual deaths worldwide. The cost for treating head injury was estimated at US \$200 million annually. This contributes to economic impoverishment in low income countries like Ethiopia. Hence, this study was aimed to assess the cost of Traumatic Head Injury (THI) and associated factors in the University of Gondar Specialized Referral Hospital.

Method: An institution-based cross-sectional study was conducted from March 01 to May 30, 2017. A total of 387 THI patients were included in the study. An interviewer-administered questionnaire was used for data collection. Direct costs and indirect costs were measured by using the bottom-up approach. Data were entered into Epi-Info version 7 and imported to SPSS version 20 for analysis. Simple and multiple linear regression analysis were done to identify factors associated with cost of THI.

Results: The mean cost of THI per patient was 4673.43 Ethiopian Birr (ETB), 95\% Cl (4523.6-4823.3), and length of hospital stay averaged $1.73,95 \% \mathrm{Cl}(1.63-1.82)$. Direct non-medical cost, like transportation fee $1896.19 \mathrm{ETB}( \pm 762.56$ SD) and medical costs 1101.66 ETB ( \pm 534.13 SD) were account for 40.57 and $23.58 \%$ of total costs respectively. The indirect cost, loss of income by patient and their attendant due to injury, was 1675.58 ETB $( \pm 459.26$ SD). Patients with moderate and severe levels of injury have 635.167 ETB (Standardized coefficient $=0.173, \bar{p}<0.001$ ) and 773.621 ETB (Standardized coefficient $=0.132, p<0.001$ ) increased costs, respectively, compared to mild level THI patients. Costs for patients ages 31-45 years were 252.504 ETB (Standardized coefficient $=-0.066, p=0.046$ ) lower than costs for those 5-14 years old. The cost of THI patients increased by 1022.853 ETB for each additional day of hospital length of stay (Standardized coefficient $=0.648, p<0.001$ ).
\end{abstract}

Conclusion: Most expenses of the THI were from direct non-medical cost. Prior health service use, length of stay, level of injury, and age were significant predictors of cost of THI.

Keywords: Cost, Traumatic head injury, Gondar, Ethiopia

\footnotetext{
* Correspondence: hsimegnew@yahoo.com; simegnew.handebo@uog.edu.et ${ }^{3}$ Department of Health Education and Behavioral Sciences, Institute of Public Health, University of Gondar, Gondar, Ethiopia

Full list of author information is available at the end of the article
}

(c) The Author(s). 2019 Open Access This article is distributed under the terms of the Creative Commons Attribution 4.0 International License (http://creativecommons.org/licenses/by/4.0/), which permits unrestricted use, distribution, and reproduction in any medium, provided you give appropriate credit to the original author(s) and the source, provide a link to the Creative Commons license, and indicate if changes were made. The Creative Commons Public Domain Dedication waiver (http://creativecommons.org/publicdomain/zero/1.0/) applies to the data made available in this article, unless otherwise stated. 


\section{Background}

Injuries are a critical public health problem worldwide which accounts for 1 of the 5 major causes of death and disability in the world. It leads to about 5 million deaths per year, which mean 16,000 deaths daily $[1,2]$. A THI is defined as any injury to the head caused by physical damage/structural change to the scalp or skull due to any type of external force with or without other body organ injury. Most common causes are falls, road accidents, collisions and violence [3].

THI will be the major cause of death and disability by the year 2020. It has been estimated that THI affects over 10 million people annually [4]. This makes THI a pressing public health and medical problem. The current evidences indicate that nearly $60 \%$ of THIs are due to road traffic injuries in all parts of the world $[5,6]$.

THI mostly occurs among people between the ages of 15 and 45 years, those believed to be the most productive members of the community. It causes substantial morbidity, disability, and mortality, and is associated with high health care costs, both for individuals and society. Additionally, members of a household might lose many productive days of their lives. This loss, when added to the costs of treatment, might push the poor household further into poverty, and it has a great impact on growth and economic development of a nation [7-10]. The average costs of THI vary significantly by age, Glasgow Coma Score (GCS), Injury Severity Score, co-existing injuries of the thorax, spine and lower limb, hospital mortality, and availability of neurosurgical services $[11,12]$.

One New Zealand study showed that 95\% THI patients had mild injury, of which approximately $64 \%$ were not initially hospitalized. Of those who were hospitalized, survivors spent on average 2.6 days (95\% CI 1.8-3.3) in the hospital. The total direct health care cost over 12 months was US $\$ 3783$ per patient (minimum US \$26, maximum US \$112,115). In addition, costs attributable to production losses were estimated US\$2000 (minimum US\$163, maximum US $\$ 13,252)$ [7].

A recent review on THI showed that in US head injury accounts for $13 \%$ of all hospitalized injuries, $70 \%$ of which were minor head injuries. The annual estimated cost of all head injuries was US\$200 million [12, 13]. Severity of injury (mild, moderate, and sever), length of hospital stay and age of participants were significantly associated with cost $[12,14]$.

Direct out-of-pocket payments incurred by households for medical services received are estimated to account for $23 \%$ of total global health expenditure and $45 \%$ of health expenditure in the developing world [15]. The Ethiopian health system is highly dependent on out-of- pocket payments by households [16, 17]. In the country, 59 and $88 \%$ of those who sought outpatient and inpatient care covered through out-of-pocket payments, respectively. The out-of-pocket payments by households contribute to about $34 \%$ of the total health expenditure in Ethiopia [18].

In order to assist health service planning, understanding factors that influence the costs (typically out-of pocket payment) is essential. THI is one of the major causes of hospitalization, disability and death in Ethiopia. Hence, the information from this study is valuable in policy, planning, and decision making related to the prevention of THI and managing the associated cost of health care services. Therefore, this study will analyze the direct out-of-pocket and indirect cost of THI at the ED of University of Gondar Specialized Hospital, Northwest Ethiopia.

\section{Methods}

\section{Study area and design}

An institution-based cross-sectional study was conducted at the University of Gondar Specialized Referral Hospital from March to May, 2017. It is one of the pioneer teaching hospital in the country. It is also a referral site for many health centers and hospitals in Northwest Ethiopia. The hospital is located in the city of Gondar in Northwest Ethiopia, nearly $727 \mathrm{~km}$ from the capital city of Addis Ababa. The hospital provides services for a population of more than 5 million people.

\section{Study population and sample size}

All THI patients treated at University of Gondar Specialized Hospital ED during the study period were included in the study. However, patients with neurological diseases before the traumatic head injury, brain injury with non-traumatic causes, or vegetative state (severe loss of consciousness) were excluded from the study. These health conditions over the cost due to previous health problem rather than merely THI. The sample size was calculated using the single population proportion formula considering the following assumptions: Proportion of traumatic head injury patients incurred above the mean cost of injury was taken to be 50, 95\% level of confidence, 0.05 margin of error and $5 \%$ non-response rate the final sample size was 403 . The average monthly traumatic head injury patient flow of the preceding year and the month prior to the actual data collection period was estimated from ED registration book. As a result, due to low THI patient flow all patients visited the hospital with THI case during the study period were involved in the study [19]. 


\section{Study variables \\ Head injury}

Defined as any injury to the brain caused by physical damage / structural change to the scalp or skull due to any type of external force to the head.

\section{Cost of traumatic head injury}

the sum of all out-of-pocket payments incurred by the patient or his family for different expenses related to the injury as well as loss of production due to the injury.

\section{Direct costs}

the sum of expenses of medical care in hospitals, transportation, laboratory tests, clinical procedures, and food and services incurred because of the injury.

\section{Direct medical costs}

the sum of all costs for consultation fee, cost of medicines, costs of investigation in the hospital.

\section{Direct non-medical costs}

the sum of all costs for transportation, food, and accommodation.

\section{Indirect costs}

represent the value of lost production because of reduced working time or impaired performance at the workplace.

\section{Severity level}

the Glasgow Coma Scale (GCS) defines the scores of $13-15,9-12$ and 3-8 as mild, moderate, and severe head injury, respectively [20].

\section{ED Length of stay}

the median time from arrival to ED departure for admitted patients and for discharged patients [21].

\section{Data collection procedures}

The patients and/or their care givers were approached for the interview in the ED after they got all necessary treatments. The questionnaire included questions about sociodemographics, wealth index, direct cost of THI, indirect cost of THI and severity level of THI. The wealth index variable was derived from the different assets of the households to assess the household cumulative wealth status. In the dataset, the wealth index were presented as "Poor", "Middle" and "high" categories. A structured, interviewer-administered questionnaire was used to collect the data. The questionnaire was also pretested in Gondar Poly health center ED with similar case patients. The direct out of pocket expenses (in ETB) for care were recorded, including hospitalization, laboratory tests, medication, transportation, and surgical procedures. The indirect cost was measured by productivity losses due to morbidity and mortality, borne by the individual and/or family members. Two supervisors and eight data collectors participated in data collection, each of whom received a one-day training by the principal investigator.

\section{Data processing and analysis}

After coding, the data were entered into EPI INFO 7 and exported to Statistical Package for Social Science (SPSS) version 20 for analysis. Descriptive statistics were computed using standard statistical parameters. After normality and homoscedasticity assumptions were checked (the outcome variable was normally distributed), simple univariate linear regression analysis was done to assess the association between each independent variable and the cost of illness. Finally, independent variables with $p$-values less than 0.2 were included in the final multiple linear regression model. Un-standardized coefficients were used to interpret effects on the dependent variable. Covariates were deemed significant if p-values were less than 0.05.

\section{Results}

Socio-demographic characteristics

Out of 403 THI patients 387 respondents participated in the study, resulting in a response rate of $96.03 \%$. Nine $(2.23 \%)$ people refused to participate and 7 $(1.74 \%)$ cases were excluded because of their expenditure on severe unrelated diseases. As presented in Table 1, the majority, 301(77.78\%), were males. One hundred fifty five $(40.1 \%)$ were farmers. One hundred thirty five $(34.6 \%)$ had a primary level education. Nearly half of the participants were age 15-30, and 193 (49.9\%) were married. The mean family size was $4.48 \pm(1.92 \mathrm{SD})$ persons per household. The mean monthly income was $3901 \pm(2503.59$ ETB SD).

\section{Injury characteristics}

Out of the study participant 101 (26.1\%) had visited other health institution prior to Gondar University Specialized hospital. The majority 192 (49.5\%), of THIs were caused by motor vehicle accidents, followed by violence 157 (40.56\%). Most of the accidents occurred between noon and midnight. Based on the GCS, 281 (72.6\%) of participants had mild THI, 79 (20.41\%) experienced moderate injuries, and 27 (6.98\%) were severe. Of the total subjects, 300 (77.5\%) were admitted to inpatient, 80 (20.7\%) were discharged from the ED within $24 \mathrm{~h}$, and 7 (1.81\%) patients died in the ED.

\section{Cost of traumatic head injury}

The mean cost per patient was 4673.21 ETB $( \pm 1499.24$

SD) with an average length of stay 1.73 days, 95\% CI (1.63-1.82). This mean incurred cost was different 
Table 1 Socio demographic characteristics of patients with traumatic head injury at University of Gondar Specialized Referral Hospital, Northwest Ethiopia $(n=387)$

\begin{tabular}{|c|c|c|c|}
\hline Characteristics & & Frequency & Percent (\%) \\
\hline \multirow[t]{2}{*}{ Sex } & Male & 301 & 77.78 \\
\hline & Female & 86 & 22.22 \\
\hline \multirow[t]{4}{*}{ Age (years) } & $5-14$ & 60 & 15.5 \\
\hline & $15-30$ & 197 & 50.9 \\
\hline & $31-45$ & 73 & 18.9 \\
\hline & $\geq 46$ & 57 & 14.7 \\
\hline \multirow[t]{4}{*}{ Occupation of respondents } & Currently not working & 44 & 11.4 \\
\hline & Civil servant & 85 & 22.0 \\
\hline & Daily labor & 103 & 26.6 \\
\hline & Farmer & 155 & 40.1 \\
\hline \multirow[t]{4}{*}{ Marital status } & Single & 189 & 48.8 \\
\hline & Married & 193 & 49.9 \\
\hline & Divorced & 2 & 0.5 \\
\hline & Widowed & 3 & 0.8 \\
\hline \multirow[t]{4}{*}{ Educational status } & Unable to read \& write & 68 & 17.6 \\
\hline & Able to read \& write & 95 & 24.5 \\
\hline & Primary level & 134 & 34.6 \\
\hline & Secondary \& above & 90 & 23.3 \\
\hline \multirow[t]{3}{*}{ Family size of respondent } & $1-3$ & 116 & 30.0 \\
\hline & $4-5$ & 156 & 40.3 \\
\hline & 6 and above & 115 & 29.7 \\
\hline
\end{tabular}

across mild, moderate and severe level of injuries $(p=$ 0.001). Direct non-medical cost 1896.19 ETB $( \pm 762.56$ $\mathrm{SD})$ and medical costs $1101.66 \mathrm{ETB}( \pm 534.13 \mathrm{SD})$ account for 40.57 and $23.58 \%$ of total costs respectively Table 2. Three hundred frothy three $(88.6 \%)$ respondents reported lost working days and income associated with their illness. The mean lost income for the attendants due to the stay at the ED was 398.23 ETB $( \pm 70.06$ $\mathrm{SD})$. Each patient had at least three family member or relatives assisting them. The mean loss of working days of the attendant was $7.68( \pm 1.06 \mathrm{SD})$ with the mean loss of income of 1277.35 ETB $( \pm 389.20 \mathrm{SD})$. Total indirect cost for the episode of THI for the patient and their relative(s) was 1675.565 ЕTB ( $\pm 459.26 \mathrm{SD})$ Table 3.

\section{Factors associated with cost of head injury}

In simple linear regression analysis sex, age, service used before arrival at ED, length of stay at ED, educational status, level of injury, type of trauma, wealth index, and family size were significantly associated with the cost of THI in the ED. The multivariate regression model was statistically significant ( $\left.\mathrm{F}_{[} 8\right], 386=41.8, p<0.000$.), and had an adjusted $\mathrm{R}$ square $=.615$. Factors significantly associated with cost of THI include: previous use of health

Table 2 Direct costs of trauma head injury patients at University of Gondar Specialized Referral Hospital Northwest, Ethiopia $(n=$ 387)

\begin{tabular}{|c|c|c|c|c|c|}
\hline \multirow[t]{2}{*}{ Variable } & & \multicolumn{2}{|c|}{ Before reaching the hospital } & \multicolumn{2}{|c|}{ At Hospital } \\
\hline & & Mean & Standard Deviation & Mean & Standard Deviation \\
\hline \multirow[t]{3}{*}{ Direct medical cost } & Card registration fee & 2.52 & .30 & 5.53 & 1.420 \\
\hline & Investigation \& procedure fee & 14.90 & 1.36 & 816.95 & 328.05 \\
\hline & Drug and emergency service fee & 34.5 & 10.15 & 227.26 & 192.85 \\
\hline \multirow[t]{2}{*}{ Direct non-medical cost } & Transportation fee & 38.10 & 11.27 & 1782.85 & 729.08 \\
\hline & Other expenses & 10.20 & 2.18 & 65.04 & 20.03 \\
\hline Total direct costs ${ }^{*}$ & & 100.22 & 25.26 & 2897.63 & 1271.43 \\
\hline
\end{tabular}

${ }^{*}$ Cost $=$ ETB 
Table 3 Indirect costs of head injury patients and attendants at University of Gondar Specialized Referral Hospital Northwest, Ethiopia $(n=387)$

\begin{tabular}{lll}
\hline Variables & Mean & Standard Deviation \\
\hline Length of stay at ED & 1.73 & 0.95 \\
Number of attendants per patient & 3 & 2.56 \\
Workdays lost by attendants & 7.68 & 1.06 \\
Workdays lost patients $^{*}$ & 2.61 & 1.16 \\
Loss of income of patients $^{*}$ & 398.23 & 70.06 \\
Loss of income of attendants $^{*}$ & 1277.35 & 389.20 \\
\hline${ }^{*}$ Cost ETB
\end{tabular}

${ }^{*}$ Cost: ETB

services at other health institutions, length of stay at ED, level of injury, and age. Patients with moderate and severe levels of injury had 635.167 ETB (Standardized coefficient $=0.173, p<0.001$ ) and 773.621 ETB (Standardized coefficient $=0.132, p<0.001$ ) higher costs, respectively, compared to patients with mild THI. Patients aged 31-45 had 252.504 ETB (Standardized coefficient $=-0.066, p=0.046)$ lower costs compared to patients in the 5-14 age group. The costs of THI patients increased 1022.853 ETB for each additional day of hospital stay (Standardized coefficient $=0.648, \mathrm{p}<0.001$ ) Table 4.

\section{Discussion}

This study investigates the cost of THI among patients attended by the University of Gondar Specialized hospital ED. THI affects mostly productive age groups. It causes substantial morbidity, disability, mortality and high health care costs, both for individuals and society $[9,10]$. In this study the mean cost of THI per patient at the ED was 4673.43 ETB, 95\% CI (4523.6-4823.3), with an average length of stay of 1.73 days, 95\% CI (1.631.82). Direct non-medical costs and direct medical costs account for 40.6 and $23.6 \%$ of total costs, respectively.

This study found that THI accounts for $33.2 \%$ of ED visits at the University of Gondar Specialized Hospital. This is higher than shown in the literature for other countries $[12,22]$. This may be due to higher prevalence of THI in low and middle income counties than in developed nations. Nearly half $(49.5 \%)$ of head injuries in Gondar were caused by motor vehicle accidents. This differs from studies conducted in the United States and Australia in which most causes of THIs were related to falls $[23,24]$.

Using the GCS, we found that $72.6 \%$ of the participants had mild THIs. This finding is similar to most previous studies, Mild THI accounts for 70 to $90 \%$ of all THI cases [23, 25]. However, it is lower than the proportion found in one New Zealand study in which nearly $95 \%$ of TBI cases were considered mild [7]. This may be due to the difference in the causes of THI; in this study almost half the THI cases were a result of motor accidents. Of the study participants, $77.5 \%$ were admitted to the hospital inpatient department and only $1.81 \%$ died in the emergency room. This finding is lower than a study conducted in England and Wales [12]. This difference may be due to differences in health care service between the study areas.

This study revealed the mean cost of THI per patient seen at the ED was 4673.43 ETB, 95\% CI (4523.6-4823.3), and the mean hospital length of stay was 1.73 days. This is lower than the findings of many other studies done in developing and developed countries [7, 12, 26, 27]. This

Table 4 Factors associated with the cost of traumatic head injury at University of Gondar Specialized Referral Hospital Northwest, Ethiopia $(n=387)$

\begin{tabular}{|c|c|c|c|c|c|c|}
\hline \multirow[t]{2}{*}{ Variables } & \multicolumn{2}{|c|}{ Un-standardized Coefficients } & \multirow{2}{*}{$\begin{array}{l}\text { Standardized Coefficients } \\
\text { Beta }\end{array}$} & \multirow[t]{2}{*}{ Sig. } & \multicolumn{2}{|c|}{ 95.0\% Confidence Interval for B } \\
\hline & $B$ & Std. Error & & & Lower Bound & Upper Bound \\
\hline (Constant) & 3190.897 & 288.326 & & .000 & 2623.953 & 3757.841 \\
\hline Sex of respondents & -69.209 & 119.243 & -.019 & .562 & -303.679 & 165.261 \\
\hline Age $31-45$ & -252.504 & 126.119 & -.066 & .046 & -500.494 & -4.513 \\
\hline Family size 4-5 & 178.577 & 115.604 & .059 & .123 & -48.738 & 405.893 \\
\hline Family size $>=6$ & 66.004 & 129.415 & .020 & .610 & -188.469 & 320.477 \\
\hline High wealth index & 243.751 & 143.618 & .064 & .090 & -38.648 & 526.150 \\
\hline Able to write and read & -4.812 & 123.414 & -.001 & .969 & -247.484 & 237.860 \\
\hline Primary education & -113.347 & 114.067 & -.036 & .321 & -337.641 & 110.947 \\
\hline Service used before Hospital & -231.149 & 117.681 & -.070 & .050 & -462.548 & .249 \\
\hline Length of stay at Hospital & 1022.853 & 58.965 & .648 & .000 & 906.909 & 1138.797 \\
\hline Moderate injury level & 635.167 & 120.675 & .173 & .000 & 397.881 & 872.453 \\
\hline Severe injury level & 773.621 & 205.557 & .132 & .000 & 369.429 & 1177.813 \\
\hline Motor bicycle accident & -81.411 & 96.620 & -.027 & .400 & -271.398 & 108.575 \\
\hline
\end{tabular}


difference may be due to differences in socioeconomic factors and health care price. Direct non-medical cost accounted for $40.57 \%$ of the total costs, and $61.5 \%$ of this cost was for transportation services. This study's findings were different from studies done in developed countries where the majority of the costs were direct medical costs $[7,12,26,27]$. This may be due to most injuries in the Gondar area occurring late at night when there is insufficient transport service availability. With regard to indirect costs, the mean loss of working days of the caregiver (typically a family member) was 7.8 , with the loss of income averaging 1277.07 ETB $( \pm 1106.695 \mathrm{SD})$.

In this study, the cost of THI was most affected by: the patient's previous use of another healthcare organization's services before coming to the ED, length of stay, level of injury, and age. The cost of THI significantly increases with the level of injuries. Moderate and severe THI patients cost 635.167 and 773.621 ETB more than those with only mild injuries. This finding is similar to those found in studies done in developed countries where mild level of injury costs lower than moderate and severe levels of THI [7, 12, 26, 27]. This is due to moderate and severe levels of injuries requiring additional medical procedures, and more laboratory and treatment services than mild injuries.

The cost of THI increased among patients who had long lengths of stay, and lower costs among those who used medical services at other health facilities prior to the ED. Patients aged 31-45 years incurred the lowest cost compared to patients aged 5 to 14 years old.

Our study was limited to a single hospital data and cost of THI care at emergency department. In addition to this, subsequent checkups and follow-up examinations were not included. Considering this, these data indicate that the cost of THI per patient is high, and the increase in the problem will negatively impact the access to quality healthcare and household's expenses. Therefore, it is suggested that an effort has to be made to reduce incidence of THI. To do so, THI prevention should be recognized as a priority activity in the health policy strategy.

\section{Conclusion}

The cost of THI is relatively high. Most of the expenses are for direct non-medical costs, like transportation. Use of health services before coming to the ED was significantly associated with lower costs of THI. Whereas, costs were significantly increased by longer lengths of stay, higher level of injury, and younger age.

\section{Abbreviations}

AOR: Adjusted Odds Ratio; Cl: Confidence Interval; ED: Emergency department; ETB: Ethiopian Birr; GCS: Glasgow Coma Scale; SD: Standard Deviation; THI: Traumatic Head Injury; WHO: World Health Organization.

\section{Acknowledgements}

The authors would like to thank facilitators and the study participants for their dedicated cooperation that made the study possible.

\section{Authors' contributions}

YA MY SH conceived the study, developed the tool, coordinated data collection, and carried out the statistical analysis and drafted the manuscript. MY SH AD participated in the statistical analysis, and drafted the manuscript. MY SH AD reviewed the drafted manuscript. All authors read and approved the final manuscript.

\section{Funding}

The authors received no specific funding for this work.

\section{Availability of data and materials}

The data underlying this findings could be accessed a reasonable request from the corresponding author Simegnew Handebo at hsimegnew@yahoo.com.

\section{Ethics approval and consent to participate}

Ethical clearance was obtained from the Ethical Review Board of University of Gondar Institute of Public Health. Letter of permission was also obtained from chief executive officer of University of Gondar Specialized Hospital. After explaining the purpose of the study written consent and assent was obtained from each patient and their parents prior to data collection. The confidentiality of information was assured by using codes. The participants were told to decline at any time if they feel uncomfortable.

\section{Consent for publication}

Not applicable.

\section{Competing interests}

The authors declare that they have no competing interests.

\section{Author details}

'Medical Ward, University of Gondar Specialized Referral Hospital, Gondar, Ethiopia. ${ }^{2}$ Department of Health Systems and Policy, Institute of Public Health, University of Gondar, Gondar, Ethiopia. ${ }^{3}$ Department of Health Education and Behavioral Sciences, Institute of Public Health, University of Gondar, Gondar, Ethiopia.

Received: 19 February 2019 Accepted: 17 October 2019

Published online: 28 October 2019

\section{References}

1. World Health Organization. Violence, injuries, and disability: biennial 2006-2007 report. Geneva, Switzerland: World Health Organization; 2008.

2. World Health Organization (WHO), Global Plan for the Decade of Action for Road Safety 2011-2020, 2010.

3. Gururaj G. Epidemiology of traumatic brain injuries: Indian scenario. Neurol Res. 2002;24(1):24-8.

4. Hyder AA, Wunderlich CA, Puvanachandra P, Gururaj G, Kobusingye OC. The impact of traumatic brain injuries: a global perspective. Neuro Rehabilitation. 2007 Jan 1;22(5):341-53.

5. Lopez AD, Mathers CD, Ezzati M, Jamison DT, Murray CJ. Global and regional burden of disease and risk factors, 2001: systematic analysis of population health data. Lancet. 2006 May 27;367(9524):1747-57.

6. Roozenbeek B, Maas Al, Menon DK. Changing patterns in the epidemiology of traumatic brain injury. Nat Rev Neurol. 2013 Apr;9(4):231.

7. Te Ao B, Brown P, Tobias M, Ameratunga S, Barker-Collo S, Theadom A, McPherson K, Starkey N, Dowell A, Jones K, Feigin VL. Cost of traumatic brain injury in New Zealand: evidence from a population-based study. Neurology. 2014;83(18):1645-52.

8. Gururaj G. An epidemiological approach to prevention-pre hospital care and rehabilitation in neurotrauma. Neurol India. 1995:43(3):95-105.

9. Scholten A. Outcome after traumatic brain injury: epidemiology, impact and assessment; Doctoral dissertation, Department of Public Health: 2016.

10. Penberthy L, Towne A, Garnett L, Perlin J, DeLorenzo R. Estimating the economic burden of status epileptics to the health care system. Seizure. 2005;14(1):46-51. 
11. Heinrich S, Rapp K, Rissmann U, Becker C, König H-H. Cost of falls in old age: a systematic review. Osteoporos Int. 2010;21(6):891-902.

12. Humphreys I, Phillips CJ, Wood RL, Macey S. The costs of traumatic brain injury: a literature review. Clin Econ Outcomes Res. 2013;5(1):281-7.

13. Runge JW. The cost of injury. Emerg Med Clin North Am. 1993;11(1):241-53.

14. McGregor K, Pentland B. Head injury rehabilitation in the UK: an economic perspective. Soc Sci Med. 1997;45(2):295-303.

15. The world health report 2006. Working together for health. Geneva: World Health Organization; 2006.

16. World Bank. Ethiopia country profile 2014. http://www.worldbank.org/en/ country/ethiopia 2014.

17. Federal Democratic Republic of Ethiopia MoH. Ethiopia's Fifth National Health Accounts, 2010/2011: Addis Ababa Ethiopia, 2014.

18. FMOH-USAID. National Health Accounts-V 2010/11. http://hfgproject.org/// EthiopiaNHAHousehold-Survey//2011. Accessed 09 January 2017.

19. Mathieson K. Making Sense of Biostatistics: Types of Probability Sampling. Journal of Clinical Research Best Practices. 2014;10(9).

20. Teasdale GR, Jennett BR. Assessment and prognosis of coma after head injury. Acta Neurochir. 1976;34(1-4):45-55.

21. National Voluntary Consensus Standards for Emergency Care. A consensus report. Washington, DC: National Quality Forum; 2009.

22. Sharma B. Road traffic injuries: a major global public health crisis. Public Health. 2008;122(12):1399-406.

23. Langlois JA, Rutland-Brown W, Thomas KE. Traumatic brain injury in the United States; emergency department visits, hospitalizations, and deaths: 2006.

24. Hawthorne G, Gruen RL, Kaye AH. Traumatic brain injury and long-term quality of life: findings from an Australian study. J Neurotrauma. 2009 Oct 1; 26(10):1623-33.

25. Cassidy JD, Carroll L, Peloso P, Borg J, Von Holst H, Holm L, Kraus J, Coronado V. Incidence, risk factors and prevention of mild traumatic brain injury: results of the WHO collaborating Centre task force on mild traumatic brain injury. J Rehabil Med 2004;36(0):28-60.

26. Campbell HE, Stokes EA, Bargo DN, Curry N, Lecky FE, Edwards A, et al. Quantifying the healthcare costs of treating severely bleeding major trauma patients: a national study for England. Crit Care. 2015;19(1):276.

27. Hunt C, Zanetti K, Kirkham B, Michalak A, Masanic C, Vaidyanath C, Bhalerao S, Cusimano MD, Baker A, Ouchterlony D. Identification of hidden health utilization services and costs in adults awaiting tertiary care following mild traumatic brain injury in Toronto, Ontario. Canada Concussion. 2016; 1(4): CNC21.

\section{Publisher's Note}

Springer Nature remains neutral with regard to jurisdictional claims in published maps and institutional affiliations.

Ready to submit your research? Choose BMC and benefit from:

- fast, convenient online submission

- thorough peer review by experienced researchers in your field

- rapid publication on acceptance

- support for research data, including large and complex data types

- gold Open Access which fosters wider collaboration and increased citations

- maximum visibility for your research: over $100 \mathrm{M}$ website views per year

At $\mathrm{BMC}$, research is always in progress.

Learn more biomedcentral.com/submissions 